\title{
A trajetória de Dom Ireneu Penna e suas escolhas como educador matemático
}

\author{
Bruno Alves Dassie \\ Letícia Maria Ferreira da Costa ${ }^{2}$ \\ João Bosco Pitombeira Fernandes de Carvalho ${ }^{3}$
}

\begin{abstract}
Resumo: O objetivo deste texto é apresentar as escolhas e a trajetória de Dom Ireneu Penna que, no Brasil, reformulou, no final da década de 1960, o ensino de Matemática no Colégio de São Bento do Rio de Janeiro a partir das propostas de Georges Papy. Foram estabelecidas relações que compõem a rede social na qual Dom Ireneu, monge beneditino e professor de Matemática, esteve imerso, e percebeu-se o quanto ela está associada à reforma ocorrida no Colégio durante o Movimento da Matemática Moderna. Entre as principais fontes utilizadas neste trabalho encontram-se o arquivo pessoal de Dom Ireneu, os depoimentos e os periódicos dos movimentos católicos da época.
\end{abstract}

Palavras-chave: Dom Ireneu Penna; Colégio de São Bento do Rio de Janeiro; Movimento da Matemática Moderna

\section{The trajectory of Dom Ireneu Penna's life and his decisions as a Mathematics educator}

In this article we will trace the decisions and the trajectory of Dom Ireneu Penna's life who, in the late 60's, based on what Georges Papy proposed, reformulated the teaching methods in Mathematics at Colégio de São Bento, in Rio de Janeiro city. We establish some relations of Dom Ireneu's social milieu and focus on those we think are directly connected to the reform headed by this benedictin monk at Colégio de São Bento during the New Math movement. Among the sources used in this work we highlight the personal data found in his "Nachlass", testimonies and catholic movements' journals of the time.

Key-words: Dom Ireneu Pena; Colégio de São Bento do Rio de Janeiro; New Math movement

\section{Introdução}

Nas décadas de 1960 e 1970, como outros países, o Brasil aderiu ao Movimento da Matemática Moderna (MMM). Ainda hoje se sentem as decorrências das ações tomadas sob a égide deste Movimento, que modificou profundamente a Matemática

1 Professor Adjunto da Faculdade de Educação da Universidade Federal Fluminense - UFF. E-mail: badassie@gmail.com.

2 Mestre em Ensino de Matemática pela Universidade Federal do Rio de Janeiro - UFRJ, Doutorando em Educação PUC-Rio. E-mail: leticia.hfc@gmail.com.

3 Professor Visitante do Programa de Pós-Graduação em Educação Matemática (Instituto de Matemática) da Universidade Federal do Mato Grosso do Sul - UFMS. E-mail: jbpfcarvalho@gmail.com. 
escolar. Grupos de estudos foram criados, novos livros didáticos foram produzidos na intenção de divulgar as novas ideias, novas experiências foram realizadas em muitas escolas do País. Vivia-se então a grande novidade da Matemática Moderna.

O Brasil, em seus múltiplos centros de formação de professores e escolas, foi palco de diversas facetas apresentadas pelo Movimento ao longo de sua existência. Seja por uma apropriação de ideias e adesão de livros didáticos estrangeiros, seja apenas pelo conhecimento do que se recomendava em países de referência como Estados Unidos e França, o Brasil experimentou ideologias diversas do Movimento da Matemática Moderna, absorvendo-as, muitas vezes adaptando-as à própria realidade e, por vezes, criando suas próprias concepções e métodos.

No estado do Rio de Janeiro, no contexto desse Movimento, citamos duas escolas que tiveram suas experiências baseadas nos livros didáticos do matemático belga Georges Papy: o Colégio de São Bento do Rio de Janeiro, na própria cidade, e o Centro Educacional de Niterói.

O Centro Educacional conheceu uma experiência liderada pelo professor Arago Backx, que estudara, na década de 1960, com o próprio Georges Papy no Centre Belge de Pédagogie de la Mathématique (CBPM), em Bruxelas. De volta ao Centro Educacional, o professor Arago esteve à frente de um projeto em sua escola que, com uma turma piloto, experimentaria por todo um segmento escolar os livros didáticos de Papy. Em entrevista, Arago comenta que "os livros de Papy são muito interessantes, mas não são para qualquer professor" (informação verbal ${ }^{4}$ ). Houve apenas uma única turma piloto, ao término da qual o método e os livros de Papy não foram mais utilizados na escola ${ }^{5}$.

O Colégio de São Bento (CSB), por sua vez, teve uma experiência bem diferente da conhecida pelo Centro Educacional de Niterói. A partir de 1967, o CSB teve seu ensino de Matemática completamente reformulado a partir das ideias de Georges Papy. Não apenas uma turma piloto, mas todas as turmas do Ensino Fundamental aderiram à nova proposta. O referido colégio viu-se na necessidade, entre outras, de produzir sua própria apostila de ensino e de adaptar a proposta de Papy para sua realidade. O professor de Matemática e monge do Mosteiro de São Bento, Dom Ireneu Penna, foi o principal personagem responsável por essa mudança. Foi por meio dele que os livros didáticos de Georges Papy começaram a fazer parte do quotidiano dos alunos. Sua influência e autoridade no colégio, dentre outros fatores, fizeram com que este modelo de ensino de Matemática permanecesse no CSB por quase três décadas.

4 Depoimento verbal concedido por Backx, Arago de Carvalho. [ago. 2012]. Rio de Janeiro, 2012. 2 arquivos .mp3 (91 min).

5 Mais detalhes dessa experiência ocorrida em Niterói podem ser encontrados em Soares (2001). 
Dessa maneira, o objetivo central deste texto é apresentar parte da trajetória de Dom Ireneu Penna e suas escolhas como educador matemático, pois concordamos com a ideia de que "no cerne de toda reforma curricular está o professor" (Kilpatrick, 2012, p. 569).

Como sugere Norbert Elias $(1994,1995)$, procuramos estabelecer o maior número possível de fios - estudos, relações humanas, pensamentos, sociedade - que compõem a rede social na qual Dom Ireneu esteve inserido e que estão associados diretamente à reforma encabeçada por esse monge. Essa rede só é compreensível em termos da maneira como os fios se unem, de sua relação recíproca. Não pretendemos aqui apresentar apenas traços de uma biografia de Dom Ireneu. Mas tampouco podemos compreender a reforma ocorrida no CSB sem analisar seu principal personagem. A separação da arte de seu artista é, nas palavras de Elias (1995) "artificial, enganadora e desnecessária" (p. 53): "Não pode ser muito correto separar o artista do homem" (p.16). Parece-nos difícil entender o conjunto de ideias e ideais que levaram a microssociedade do CSB a se embrenhar pelos caminhos de uma reformulação de seu ensino de Matemática, liderada por Dom Ireneu, sem tentar compreender o significado de tal impacto para seu desenvolvimento como professor, educador matemático, filósofo e indivíduo atuando em uma determinada época.

Entre as principais fontes utilizadas neste trabalho, citamos o arquivo pessoal de Dom Ireneu, os depoimentos de professores e ex-alunos e os periódicos dos movimentos católicos da época6.

\section{Um homem de seu tempo}

Weimar Penna, como foi batizado Dom Ireneu ${ }^{8}$, nasceu em 1916 em São José dos Campos, no estado de São Paulo. Seu pai, Alexandre Moreira Penna, era filho do Conselheiro Affonso Augusto Moreira Penna, presidente do Brasil de 1906 a 1909. A ida de Weimar para a cidade do Rio de Janeiro, nessa época Distrito Federal do País, ocorreu quando ele era ainda menino. Tendo aprendido as primeiras letras no lar com sua mãe, ingressou no Lycée Français do Rio de Janeiro, atual Colégio Franco Brasileiro, onde cursou o primaire (duração de quatro anos) e o sécondaire (duração de cinco anos). Em 1931, deixou o Lycée, tendo aí adquirido maestria da língua francesa, absorvido e vivido a cultura clássica francesa e tendo deixado seu nome gravado nos anuários que listavam os alunos que melhor se destacaram no colégio.

6 Este artigo apresenta parte dos resultados da pesquisa desenvolvida em nível de Mestrado (Costa, 2014).

7 Uma versão mais ampliada sobre a trajetória de Dom Ireneu Penna foi apresentada no Segundo Encontro Nacional de Pesquisa em História da Educação Matemática, em Bauru-SP.

8 Ao ingressar em um mosteiro, no dia em que recebe o hábito monástico, o candidato escolhe um novo nome em sinal de sua morte para o mundo e nascimento para uma nova vida. 
Seu pendor pelas ciências exatas o levou então, em 1937, a diplomar-se em engenharia civil pela Escola Politécnica do Rio de Janeiro. Nesse mesmo ano, concluiu o curso de licenciatura de dois anos na Escola de Ciências da recém-fundada Universidade do Distrito Federal (UDF) para tornar-se professor secundário de Matemática.

Duplamente certificado, como engenheiro e como professor, Weimar Penna atuou muito mais na área de educação do que no campo próprio da engenharia. Em 1938, foi nomeado para o cargo de oficial de gabinete do Secretário Geral de Educação e Cultura do Distrito Federal (Notícias da Prefeitura, 1938; Pedras Vivas, 2008, p. 58). Nesse cargo permaneceu só por alguns meses. Em julho de 1938, foi desse dispensado por ter sido nomeado para outro cargo público, a saber, o de professor adjunto da 12a Seção de Didática da Universidade do Distrito Federal $^{9}$ (Gabinete do Prefeito-Br., 1938a). Como professor da UDF, Weimar Penna chegou a participar de bancas de concursos de habilitação de pessoal, na área de Lógica, pela Escola de Educação (Universidade do Distrito Federal-Br., 1938). A cena então se repete. Novamente Weimar deixou um cargo com poucos meses de trabalho. Ainda em finais de 1938, ele retornou à Secretaria Geral de Educação e Cultura, dessa vez como professor. Tendo prestado concurso público para professor da escola técnica secundária da Secretaria Geral de Educação e Cultura, foi classificado e tomou posse no dia 16 de novembro de 1938. Passou, então, a ocupar o cargo de professor do Departamento de Educação, alocado na 3a Seção, que compreendia as áreas de Matemática, Matemática aplicada e Estatística (Secretaria de Educação e Cultura- Br., 1938). Apenas onze dias após ter sido nomeado para exercer esse cargo, foi designado pelo prefeito do Distrito Federal, Henrique Dodsworth, para fazer estudos especiais do ensino de Filosofia na Universidade de Paris (Sorbonne), além de realizar, pelo período de um ano, uma análise dos sistemas escolares na França e na Inglaterra (Gabinete do Prefeito-Br., 1938b). Weimar reapresentou-se à Secretaria Geral de Educação e Cultura em 30 de outubro de 1939 (Divisão de Secretaria-Br., 1939), ano em que estouraria a Segunda Guerra Mundial na Europa.

Formado em Engenharia, Weimar dedicou mais sua vida e estudos posteriores a questões sociais e intelectuais do que a problemas estritamente tecnológicos. Quando percebemos que as décadas de 1920 a 1940, no Brasil, foram períodos de transformações decisivas nos planos econômicos, social (expansão das profissões de nível superior), político e cultural (criação de novos cursos superiores, expansão da rede de instituições culturais) e que, consequentemente, como aponta Miceli (2001), esses períodos “se caracterizaram pela presença do engenheiro no domínio

9 Nesse ano era reitor da UDF Afonso Penna Júnior, tio de Weimar Penna. 
dos estudos sociais" (p. 117), compreendemos a qualificação de Dom Ireneu como "um homem de seu tempo" (Maria, 2007, p. 332). A atuação de Weimar Penna em cargos de interesses político-sociais tão logo se diplomara, seu trabalho como professor de Matemática, tanto em nível secundário quanto em nível universitário, sua cultura clássica e seu interesse pelos estudos sociais era algo comum para a sociedade de sua época. Miceli (2001) comenta que

a presença dos engenheiros nas áreas de estudos sociais, do pensamento político, da produção de obras pedagógicas, no exercício de cargos administrativos em instituições escolares ou entidades e associações corporativas ou, então, assumindo o trabalho executivo de implementar as reformas da instrução em curso explica-se, de um lado, pela formação humanista e letrada que subsistia nas escolas politécnicas desde os tempos do Império e, de outro, pelas transformações por que passava o mercado de postos destinados aos detentores de diplomas superiores. (pp. 117-118)

Nessas décadas, viam-se engenheiros que "dispunham de um mínimo de aptidões culturais para se lançarem em novas especializações do trabalho intelectual" (Miceli, 2001, p. 118). Ser considerado um intelectual não era status reservado a bacharéis em Direito, um curso mais próximo da atividade intelectual do que a Engenharia e a Medicina, na atual visão dessas disciplinas. Ainda na perspectiva de Miceli (2001), podemos considerar Weimar como um pertencente ao grupo dos intelectuais brasileiros das décadas entre 1920 e 1945. Mais do que isso, Weimar Penna foi o que se denominou um intelectual leigo, incorporado especificamente a um núcleo que atuava como porta voz dos interesses da Igreja Católica.

A partir do início da década de 1920, a Igreja Católica empreendeu esforços para "criar uma rede de organizações paralelas à hierarquia eclesiástica e geridas por intelectuais leigos" (Miceli, 2001, p. 127), na intenção de ampliar sua atuação política e divulgar o pensamento católico em Filosofia, Teologia, História, Política, Educação, entre outros assuntos. É nesse contexto que surgem, no Rio de Janeiro, o Centro Dom Vital e a revista A Ordem, vinculada ao Centro. Fundado em 1922 por Jackson de Figueiredo, o Centro Dom Vital, juntamente com A Ordem, congregava os intelectuais católicos que se reuniam para assistir aos cursos e ministrá-los, difundir seu posicionamento acerca de inúmeras questões temporais, divulgar questões de Filosofia, Sociologia e Teologia. Para a Igreja Católica e seus fiéis, o Centro e suas publicações eram uma referência nos mais diversos assuntos. O arcebispo do Rio de Janeiro, Dom Sebastião Leme da Silveira Cintra, Cardeal Leme, atestou, em 1938, que "o Centro Dom Vital é a maior afirmação da inteligência cristã em terra do Brasil" (A Ordem, 1938, p. 2). O Centro tinha sua importância, reconhecida em diversas 
cidades brasileiras ${ }^{10}$. Ressaltamos aqui que, durante os anos de 1936 a 1938, Weimar Penna teve contato direto com os órgãos intelectuais católicos de sua cidade, notadamente com o Centro Dom Vital.

Em relação a seu desenvolvimento filosófico, Weimar aproveitou sua viagem à França, realizada entre 1938 e 1939, para aprofundar seus estudos sobre a filosofia de Santo Tomás de Aquino e estreitar relações com o filósofo Jacques Maritain, frequentando seu curso de Filosofia no Institut Catholique de Paris. O pensamento do filósofo tomista Jacques Maritain era difundido e compartilhado, seus livros traduzidos e disponibilizados aos integrantes do Centro Dom Vital. Os ensinamentos de Santo Tomás de Aquino, juntamente com os comentários e as elucidações de Maritain, formavam a base filosófica dos intelectuais leigos católicos do Centro Dom Vital. A filosofia tomista seria para Weimar o parâmetro e a luz em todos os assuntos. Seguindo a corrente filosófica realista, ele se oporia contundentemente às concepções filosóficas idealistas, sobretudo no tangente à educação ${ }^{11}$.

Weimar teria sua vida inteiramente modificada a partir de 1941, quando ingressou na Abadia de Nossa Senhora de Montserrat do Mosteiro de São Bento, pertencente à ordem beneditina e instalada na cidade do Rio de Janeiro. Sobre o Centro e suas vocações Miceli (2001) comenta que

sob sua égide [do Centro Dom Vital] foram organizados os retiros para intelectuais onde se promovia o encontro dos aspirantes às carreiras intelectuais com os mestres do clero em matéria de doutrina. ... O saldo mais importante do trabalho desenvolvido por tais agremiações [Ação Católica Universitária, Juventude Católica Universitária, Instituto Católico de Estudos Superiores] foi o surto de vocações entre jovens intelectuais originários de antigas famílias que decidiram ingressar nas ordens religiosas de maior prestígio (os beneditinos, os jesuítas, os dominicanos). (p. 128)

Weimar Penna pediu para entrar no noviciado do Mosteiro de São Bento em 1941 e aí recebeu o nome de Ireneu. Foi ordenado sacerdote em 1947 e, nesse mesmo ano, entre as diversas funções que passou a acumular, começou a dedicar-se ao Colégio de São Bento, no qual permaneceria como professor de Matemática até 1976. No Colégio, foi ainda professor de Religião, Desenho e Filosofia.

10 Decorridos 14 anos desde sua fundação, o Centro contava com representações congêneres em 12 outras cidades: São Paulo, Belo Horizonte, Salvador, Porto Alegre, Fortaleza, Recife, São João Del Rey, Aracaju, Juiz de Fora, Itajubá, Ouro Preto e Uberaba.

11 O leitor interessado na argumentação de Dom Ireneu contra o ensino idealista pode reportar-se a Registro e comentários - Centro Dom Vital (1951, novembro). A Ordem, 46(5),1951, ou Penna, I. (1952, abril). A influência de um ideal na Educação. $A$ Ordem, 47(4), 4-14. 


\section{Dom Ireneu e o método Papy}

Concomitantemente à sua vida de sacerdote e monge, Dom Ireneu foi um professor ativo e muito considerado tanto dentro do Mosteiro de São Bento e suas dependências quanto fora dele. Na Faculdade de São Bento, sob a direção do Mosteiro de São Bento, Dom Ireneu foi o professor de Filosofia e de Metafísica de muitas gerações de monges. Além da atuação na Faculdade de São Bento, Dom Ireneu voltou, então como monge, a lecionar na Universidade. De 1957 a 1968, lecionou Filosofia na Universidade Federal do Rio de Janeiro (UFRJ) (Universidade Federal do Rio de Janeiro-Br., 1969). Apreciado e respeitado pelos catedráticos universitários e por seus alunos, amante de seu trabalho com a Filosofia, Dom Ireneu ver-se-ia levado a pedir afastamento de seu cargo de professor. Em sua carta demissionária, explicou sua decisão:

A situação atual [decorrente do que ficou conhecido como Movimento Estudantil de 1968], conhecida de todos, exige para o lugar que vinha ocupando predicados e condições fáceis de encontrar em inúmeras pessoas do inteiro agrado da maioria (ou, se preferir, da minoria vociferante) dos alunos, mas que absolutamente não se acham realizados em mim. (Penna, 1968b)

Deixando então a UFRJ, Dom Ireneu ingressou naquele mesmo ano como docente na Universidade Santa Úrsula (USU), onde por cinco anos ensinaria Fundamentos de Matemática I e II e Lógica Moderna. Foi nesse momento que tomou conhecimento das produções de Georges Papy e iniciou o trabalho de implementação do método Papy no Colégio de São Bento, ao mesmo tempo em que estreou esses livros didáticos com seus alunos da USU. Foi a alunos desse grupo, formado por mulheres em sua maioria, que Dom Ireneu dirigiria seu convite para lecionar Matemática no CSB.

Sabemos ainda que Dom Ireneu frequentou cursos relacionados à Psicologia e à Educação. Enquanto foi professor, completou diversos estudos relacionados à prática docente e à filosofia da educação; inclusive diplomou-se (1953-1954) em Orientação Educacional e Pré-profissional pela Fundação Getúlio Vargas (FGV). Ainda na FGV, estagiou por dois anos estudando testes psicológicos e educacionais no antigo Instituto de Seleção e Orientação Profissional (ISOP) (Ficha, 2008).

Sabemos que estudou Matemática, de maneira autônoma, dentro do mosteiro, como pode ser verificado em seu arquivo pessoal. Inúmeros são os cadernos manuscritos que se encontram em seu acervo com anotações, comentários, exercícios resolvidos, curiosidades matemáticas, de autores como Birkhoff e MacLane (Álge- 
bra), Emile Fourrey, Lauro Sodré Viveiros (Probabilidade e Estatística), e inclusive de Boécio (De Arithmetica) e do próprio Euclides, ambos em latim. Tudo isso revela a importância e o apreço que Dom Ireneu dava à ciência. $\mathrm{O}$ estudo da Matemática era uma constante em sua vida monástica.

\section{A eleição do método Papy no Colégio de São Bento}

Dom Ireneu era um educador inconformado com o ensino de Matemática de sua época. José Paulo Carneiro, professor de Matemática do científico no CSB no início da década de 1970, comenta que “era o império de Ary Quintela”, em cujos livros-texto a álgebra e a geometria eram vistas como duas coisas completamente divorciadas. Um assunto não tinha relação com o outro e demonstrações eram usuais apenas em Geometria ${ }^{12}$. Ainda segundo José Paulo Carneiro, Dom Ireneu não se conformava com a falta de coerência entre os diversos assuntos de Matemática ensinados no colégio, nem com a maneira como os alunos eram introduzidos às ciências matemáticas, por meio dos livros-texto disponíveis.

Como coordenador de Matemática e coordenador do ensino ginasial no CSB na década de 1970, Dom Ireneu sempre mostrava novos livros ao professor Carneiro, que o acompanhava em sua busca por algo ideal para suas aulas de Matemática. Foi assim que, em 1967, Dom Ireneu adquiriu os primeiros volumes da coleção Mathématique Moderne ${ }^{13}$, de Papy, e a apresentou ao professor Carneiro, junto com seu entusiasmo, já lhe confiando sua vontade de adotá-la em suas aulas:

Dom Ireneu sempre me mostrava livros - e tem outros [de] que eu não me lembro o nome. ... Até o dia em que exatamente ele me trouxe o Papy. ... A essência do Papy era exatamente essa mistura constante, essa mescla constante entre geometria e o resto da matemática. Ele acabou com esse negócio de separar a geometria. Desde o início então ele vai fazendo geometria, e vai fazendo uma geometria axiomática correta. Obviamente Dom Ireneu ficou encantado com isso e chegou pra mim - lembro disso lá na sala dos professores do São Bento - e me disse assim: "Se eu agora formar as turmas por aqui - porque eu finalmente encontrei um sistema coerente - você aguenta eles lá no fim [nos três anos de científico]?" (J.P.Carneiro, comunicação pessoal, julho, 2012)

12 Ary Quintela foi autor de diversos livros didáticos de Matemática. Apesar de não apreciar a condução que Ary Quintella dava aos conteúdos, Dom Ireneu apreciava as "correções" feitas nas novas edições e acreditava em uma tendência a melhorar: "Certos compêndios aparecem profundamente corrigidos nas novas edições. O de Ary Quintella, do $3^{\circ}$ ginasial, merece elogios” (Dom Ireneu citado por Fernandes, 1968).

13 Dom Ireneu adquiriu os primeiros volumes da coleção na edição de 1966. Estes volumes ainda se encontram em seu acervo pessoal. 
À resposta afirmativa do professor Carneiro, Dom Ireneu decidiu, então, adotar os conteúdos e a metodologia expostos na coleção Mathématique Moderne, de Papy, para os quatro últimos anos do ensino ginasial do CSB. Para os três anos do ensino científico, manter-se-ia o ensino tradicional da época. Mesmo sendo difícil a passagem de um ciclo para outro, os professores acharam que valia a pena. A ex-professora Sandra Carelli, uma pupila de Dom Ireneu quando esse lecionava na Universidade Santa Úrsula, comenta que, para adotar o método Papy, o professor tinha que estar convencido de todo o fruto e toda a riqueza que ele proporcionava. E acrescenta que os professores do científico - e aqui podemos citar o professor José Paulo Carneiro como uma exceção - não pensavam como Dom Ireneu (S. Carelli, comunicação pessoal, fevereiro, 2013). Achavam, primeiramente, que não havia necessidade de ser "tão fiel de mais" ao Papy como Dom Ireneu era (o que não o impediu de dar também sua contribuição ao ensino no CSB), e segundamente, sentiam-se pressionados pelos resultados que deveriam alcançar nos exames de vestibular.

Essas divergências com os professores do ensino científico de certa forma dificultaram a adoção do método e contribuíram para que ele só se desenvolvesse nas séries ginasiais. Mas Dom Ireneu recebeu todo o apoio do reitor do Colégio, Dom Lourenço de Almeida Prado, como relatado também por José Paulo Carneiro (comunicação pessoal, julho, 2012). Esse apoio do reitor mostrou-se fundamental para o desenvolvimento do método Papy e sustentou a autoridade de Dom Ireneu nas séries ginasiais. Dom Lourenço, porém, não concordava que o método fosse estendido para o ensino científico, e de fato, neste segmento que antecede o vestibular, o método nunca foi adotado. Dom Lourenço temia de certa forma o desempenho dos alunos nos exames de vestibular. Devemos ressaltar que Dom Ireneu não coordenaria o ensino de Matemática nos novos moldes propostos por Papy no ensino científico. Essa coordenação estava a cargo de outro professor. Dom Ireneu, apesar de coordenador da disciplina, era apenas coordenador do ensino ginasial, fugindo assim de sua alçada a decisão de adotar ou não o método nas séries do científico, assim como sua condução.

\section{Razões da escolha do método Papy}

Se o espaço de Matemática era de Dom Ireneu, se ele tinha a liberdade para decidir sobre novos conteúdos e metodologias, as responsabilidades inerentes a essas decisões relativas à disciplina Matemática também pertenciam a ele. Assim que o colégio introduziu o método Papy em suas aulas de Matemática do ginásio, Dom Ireneu escreveu uma circular aos pais e responsáveis pelos alunos da 1ạ série ginasial prevenindo-os quanto a essa recente mudança no ensino da disciplina no colégio. Dessa carta, apreendemos as razões da escolha de Dom Ireneu: 
Como a totalidade de manuais brasileiros disponíveis começou a introduzir os novos métodos e conceitos, sem porém alterar substancialmente a ordem das matérias e pontos tradicionalmente abordados, à medida que íamos expondo os conceitos fundamentais de Matemática pelos novos métodos, a própria necessidade de coerência nos foi distanciando desses manuais, obrigando-nos a fornecer aos alunos textos mimeografados das lições de exercícios. Na verdade, não era nossa intenção inicial enveredar por esses caminhos, quanto mais não fosse pelo maior trabalho que daí nos adviria. (Penna, (1967-1970))

É possível que uma das mais fortes objeções feitas ao colégio quanto à adoção do novo método tenha sido em relação a não utilização dos livros didáticos brasileiros de Matemática Moderna que circulavam na época. Dom Ireneu dizia explicitamente que, a julgar pelos compêndios que conhecia - e nessa lista incluía "o que foi publicado pelo professor Castrucci, de competência reconhecida” (Penna, (1967-1970)) - a Matemática Moderna não vinha sendo bem ensinada no Brasil. Para ele, o defeito essencial residia mais no como eram ensinados os conteúdos, e com qual ênfase eram abordados, do que nos conteúdos em si. Um amigo de Dom Ireneu e antigo professor de matemática do Colégio de São Bento, interrogado sobre as razões pelas quais ele se recusava a seguir os livros didáticos propostos pelos que difundiam o MMM, respondeu: "Porque repugnava a um cara como Dom Ireneu, como a mim e a outros, fazer coisas mal feitas” (J. P. Carneiro, comunicação pessoal, julho, 2012). Também desagradava a Dom Ireneu a falta de rigor estampada nos livros didáticos tradicionais. Especificamente sobre os diagramas, Carelli (comunicação pessoal, fevereiro, 2013) explica que o rigor na representação dos conjuntos era, para Dom Ireneu, um ponto capital, e nos livros didáticos de Papy tudo era feito com o máximo de rigor. Dom Ireneu rejeitava todo "diagrama com figuras"14, o que, para ele, trazia confusão e recaía em erros. Preferia outras ferramentas, como o diagrama de Venn e o diagrama de flechas de Papy, que acreditava serem muito preciosas. Ele confiava no método que elegeu e acreditava que a iniciação feita por meio da Matemática Moderna, ao modo de Georges Papy, garantia bases muito mais sólidas para os estudos superiores, em todos os ramos do conhecimento. Em uma entrevista concedida ao jornal do CSB intitulado O Leão, Dom Ireneu expõe seu pensamento:

[A] MM exerce um apelo mais universal sobre as inteligências. Dá a impressão de "um jogo mais limpo", onde tudo é posto às claras e nada se escamoteia.

14 Dom Ireneu chamava "diagramas com figuras" a todo desenho de um conjunto com uma quantidade n de elementos idênticos entre si, como era muito comum encontrar em livros didáticos para séries iniciais. $\mathrm{O}$ problema reside no fato de que um conjunto com $n(n \neq 1)$ elementos idênticos entre si não possui de fato n elementos, mas apenas um único elemento. Dom Ireneu não admitia que se desenhasse um conjunto com seis árvores de desenhos idênticos e se dissesse que o conjunto possuía seis elementos. 
Tem recursos geniais para matematizar as situações concretas..., fornecendo esquemas lógicos e hábitos de pensamento que se estendem a todos os ramos do saber [itálico nosso]. (Dom Ireneu citado por Fernandes, 1968, p.3)

De fato, após o estudo de um novo modelo matemático, Dom Ireneu tentava fazer uma tradução concreta dele com seus alunos. Assim, foram construídos circuitos elétricos e calculadoras a partir das tabelas-verdade da lógica. Ainda a respeito da matematização de conteúdos, apresentamos o testemunho de um ex-aluno que relembra essa concretização de um conteúdo de álgebra e de lógica:

Outra curiosidade era o computador booleano, que eu também reproduzi em casa... Eram quatro chaves de duas posições, cada uma com 12 polos, quatro lâmpadas e uma bateria. Os polos das chaves eram trazidos à superfície do computador, em "jacks". Com cabos contendo "plugs", podíamos interligar os polos das chaves, da bateria e das lâmpadas. Pronto o computador, vinha a programação: montávamos a tabela verdade da função desejada, "codificávamos" com os cabos e, pronto: as lâmpadas acendiam de acordo com a tabela verdade. Um dos problemas que ele gostava era o de atravessar um homem, uma onça, um cabrito e uma cenoura de um lado para outro do rio; quando uma situação indesejada ocorria (a onça foi deixada sozinha com o cabrito), uma lâmpada acendia! E ele me deixou um desafio, que era fazer um somador binário com chaves de 18 polos. Ele conseguiu fazer e não deixei ele me contar a solução, pois eu também queria resolver... Durante alguns anos, tentei resolver, sem sucesso, e eu acabei esquecendo. O tempo passou, ele morreu e o desafio ficou... (Miranda, comunicação pessoal, maio, 2011)

Quanto aos referidos "hábitos de pensamento que se estendem a todos os ramos do saber", compreendemos o conjunto de situações e problemas de Matemática com os quais os alunos de Dom Ireneu se deparavam e que os faziam perceber, entre outras coisas, que a Matemática não era um simples manejar de números. Por exemplo, o aluno devia perceber que, ao ler um enunciado, não bastava apanhar os números e fazer uma conta. Tinha que haver uma crítica, um raciocínio baseado no enunciado. E esse é um hábito de pensamento, extensivo a qualquer ciência.

Outro aspecto sobre o qual Dom Ireneu insistia muito era a questão da ordem lógica dos conteúdos. Para que houvesse uma honesta construção do "edifício da Matemática”, fazia-se necessária grande coerência entre os diversos conteúdos. Na sequência proposta por Georges Papy, Dom Ireneu percebia essa coerência (Penna, 1974).

Para Dom Ireneu, "a preparação em matemática moderna dá uma visão mais ampla e mais correta" sem deixar "de habilitar o estudante a resolver os problemas tradicionais" (Penna, 1968a, p. 1). Infere-se daí que as inquietações dos pais e de alguns educadores a respeito de como os alunos oriundos de um sistema muito 
diferente do proposto pelos programas usuais da época se sairiam nos exames de vestibular não eram compartilhadas por Dom Ireneu. Ele parecia ter certeza do êxito de seus alunos nos vestibulares, pois acreditava que a formação da inteligência que eles receberiam ia muito além do exigido pelos exames realizados no Brasil. $\mathrm{O}$ sucesso era então efeito, e não a meta visada. Era uma manifestação dos "hábitos de pensamento" desenvolvidos à medida que o aluno era exposto a situações que construíam o “edifício da Matemática”. Era uma aplicação às outras disciplinas desses hábitos desenvolvidos na Matemática.

No trecho a seguir, retirado de um artigo escrito no periódico O Globo, Dom Ireneu solicita a confiança dos pais quanto ao trabalho que ele desenvolvia no CSB: "Os pais devem confiar que nós estamos aplicando um método qualitativamente superior" (Penna, p. 26). De fato, era preciso confiança não só em Dom Ireneu, mas no conjunto formado pela própria instituição CSB, pelos professores e pelo reitor, Dom Lourenço de Almeida Prado. Dom Ireneu deu mostras de ser um educador que via muito à frente e que, ao mudar radicalmente o currículo de Matemática das séries ginasiais, não temeu que o colégio fosse retirado dos patamares nos quais sempre se manteve. O sucesso dos alunos do CSB nos exames públicos, nessa época, pode ser confirmado por diversas fontes. Soares (2001) comenta esse fenômeno, além de apontar depoimentos de professores do ensino básico e universitário que testemunham que "um aluno do colégio é facilmente distinguido entre os demais por apresentar raciocínio rápido e melhor desempenho na resolução de problemas" (Soares, 2001, p. 98).

Ao comentar que "bem cedo [os alunos] terão contato com as partes mais vivas da matemática, usualmente só estudadas mais tarde, com real prejuízo para os cursos de nível superior" (Penna, (1967-1970)), acreditamos que Dom Ireneu se referia a conteúdos tanto de álgebra - grupos, anéis - quanto a temas usuais naquilo que hoje se denomina análise - a estrutura dos números reais, a enumerabilidade de conjuntos e questões sobre o infinito. Pois ainda na mesma circular aos pais, Dom Ireneu comenta que os alunos "abordarão as questões do infinito matemático com um perfeito rigor lógico que os preparará corretamente para o cálculo diferencial e integral" (Penna, (1967-1970)). E, de fato, todos esses tópicos constam tanto das apostilas de conteúdo elaboradas por Dom Ireneu quanto dos livros didáticos de Georges Papy. É de se notar a grande preocupação em preparar o aluno, desde as séries ginasiais, para "o cálculo diferencial e integral" visando a uma instrução profunda em todas as disciplinas, desde as mais tenras idades. Assim, todos os alunos, independentemente da carreira que seguiriam ao deixar a escola, teriam acesso considerável tanto ao manejo inicial do cálculo quanto às letras e à literatura.

A abordagem vetorial, muito enfatizada na proposta de Georges Papy, também 
é uma característica apreciada por Dom Ireneu. Ele percebia o cálculo vetorial como o laço que une a geometria analítica à álgebra. Para Dom Ireneu, os alunos teriam, com sua proposta, "o manejo inicial do mais poderoso instrumento de cálculo e teorização que é o cálculo vetorial e começarão a se familiarizar com a geometria analítica” (Penna, (1967-1970)), muito antes do que costumava acontecer. Essa antecipação era, para Dom Ireneu, uma vantagem.

A partir desse entendimento de Dom Ireneu em relação ao tipo de ensino de Matemática que seus alunos deveriam ter, percebe-se mais uma vez a elevada formação científica desejada pelo corpo de professores do CSB. Além disso, ficam realçados com brilhantismo o entendimento e o conhecimento relativo à Matemática do próprio Dom Ireneu.

Mas não se tratava apenas de uma questão de aquisição de elevada formação científica, inclusive porque Dom Ireneu tinha consciência de que nem todos os alunos chegariam ao nível desejado por ele. "A gente se contenta com o menos de uns e o mais de outros", comentou Penna (1974, p. 26)

A adoção do método Papy significava, sobretudo, a escolha de um método perspicaz, que contribuía para a formação da inteligência do indivíduo. Em diversas entrevistas, Dom Ireneu sublinha esta característica "inteligente" do método adotado e de que maneira se dá a colaboração da Matemática Moderna para o aperfeiçoamento do raciocínio.

\section{Considerações finais}

Um testemunho considerável para compreendermos a decisão de Dom Ireneu pelo método Papy é o de José Paulo Carneiro, haja vista a proximidade existente entre esse professor, Dom Ireneu e o método Papy. Como visto, Carneiro foi professor do então curso científico no CSB, nos primeiros anos em que vigorou o novo currículo, e foi um dos braços direitos de Dom Ireneu nessa época:

O Dom Ireneu, eu conheci muito ele. Era amigo dele. ... Ele era uma pessoa extremamente inteligente, uma das pessoas mais inteligentes que eu já conheci. Inteligência geral que eu quero dizer, não só matemática. Inclusive você sabe que ele foi professor de Filosofia. E ele se dedicava muito ao colégio. ... Ele era um monge que se dedicava de uma maneira muito especial [ao Colégio] e especialmente ao ensino de matemática. Ele era muito dedicado, fazia coisas, por exemplo, que nenhum outro professor faz. Ele tinha uma mania de passeio, passeio com os alunos: ia subir montanhas. Ele já caiu, quebrou a perna, e ele ligava um pouco isso aos estudos, dava prêmios. Havia o concurso Lélio Gama. Era um cara muito bem educado. Agora, por outro lado, ele era uma pessoa um pouco difícil. ... Não era uma pessoa risonha, não. Ele 
era aquela pessoa inconformada, perfeccionista no sentido meio mau da palavra. ... Ele era um pouco intolerante para as coisas, ... um pouco difícil, um pouco radical. ... Mas repito, era extremamente inteligente e difícil, e completamente inconformado com o ensino de matemática tradicional. (J.P.Carneiro, comunicação pessoal, julho, 2012)

Nas entrelinhas desse e de seus próprios testemunhos, Dom Ireneu deixa entrever sua concepção tanto de educação matemática quanto de ensino e educação geral do homem: busca-se ensinar o aluno a pensar, organizar o raciocínio, convidar o aluno a conhecer, a utilizar e desenvolver sua inteligência e assim alcançar a verdade, entender a realidade. Dom Ireneu servia-se da Matemática para desenvolver, nos alunos, os "hábitos de pensamento" que iam além do conteúdo matemático, tais como, relacionar causa e consequência, partir de axiomas e chegar a conclusões, generalizar, relacionar fatos a outros fatos, utilizar um mesmo conteúdo/raciocínio em uma situação diferente.

Percebemos também que as atitudes e os pensamentos de Dom Ireneu caminham, em alguns aspectos, em consonância com as concepções de educação de Dom Lourenço de Almeida Prado (1991). Em um de seus livros sobre o tema, o ex-reitor do CSB expõe sua visão sobre o que é Educação:

No cerne do processo educativo está a verdade [itálico do autor], ... o conhecimento da verdade e sua conquista. O homem é um animal curioso, um animal que tem sede de saber e se alegra com a descoberta da verdade. A inteligência precisa da verdade, como de seu alimento. É iluminado pela verdade, aos poucos conquistada, que o ser humano vai se equipando com a faculdade de discernir, avaliar e escolher, de ponderar e decidir. (p.27)

É nesse contexto filosófico sobre o que é Educação que se devem entender as decisões e a escolha de Dom Ireneu pelos conteúdos e pela metodologia apresentados por Georges Papy para o ensino de Matemática. No Prefácio da 1a edição dos Apontamentos de matemática II ${ }^{15}$, Dom Ireneu (197-), após citar os conteúdos abordados nesse volume dos apontamentos, (essencialmente "o estudo de certas funções para a construção de certos grupos”), conclui:

Eis aí um programa para um ano de estudo cheio de conteúdo, pelos seus temas novos e importantes, cheio de virtualidades de formação da inteligência e do raciocínio, cheio de atração pela alegria do saber que é, no dizer do Filósofo, o traço distintivo da grandeza do homem. (Penna, [197-], prefácio).

15 Os Apontamentos de Matemática, em 4 volumes, foram apostilas de conteúdo elaboradas por Dom Ireneu com base nos volumes da coleção Mathématique Moderne de Papy, para uso dos alunos do CSB. 
Percebemos, assim, os traços de seus estudos anteriores e o sustento filosófico e intelectual que permeava as decisões de Dom Ireneu como professor e onde se apoiava o desenvolvimento de seu trabalho.

Uma interpretação a ser desenvolvida, que foge do escopo deste artigo, é a relação entre a duração e o bom andamento do método Papy no Colégio São Bento e o alto prestígio que Dom Ireneu possuía. $\mathrm{O}$ que podemos apontar, à guisa de conclusão, é que, conhecido na esfera educacional de sua época por seus trabalhos e conhecimentos, apreciado e louvado como professor e como educador tanto fora quanto dentro de seu meio de trabalho, Dom Ireneu conseguiu transpor muitas dificuldades políticas e educacionais ao tentar fazer-se escutar e obedecer quando decidiu implantar o método Papy no CSB. Podemos dizer que o prestígio filosófico e pedagógico do qual fruía - o que lhe outorgava respeito e confiança - também lhe foi favorável no momento de argumentar com os pais e com a mídia quanto à importante mudança no ensino da Matemática no Colégio de São Bento.

\section{Referências}

A Ordem. (1921-1976, mensal). Rio de Janeiro: Centro Dom Vital.

Costa, L.M.F. da (2014). O movimento da matemática moderna no Brasil: o caso do Colégio de São Bento do Rio de Janeiro. Dissertação de Mestrado em Ensino de Matemática. Rio de Janeiro: Universidade Federal Fluminense.

Divisão de Secretaria do Distrito Federal- Br. Expediente do Sr. Secretário Geral (1939, 31 de outubro) Diário Oficial. 01 (nov). Seção II, 1905.

Elias, N. (1994). A Sociedade dos indivíduos. Rio de Janeiro: Zahar.

Elias, N. (1995). Mozart: sociologia de um gênio. Rio de Janeiro: Zahar.

Ficha biográfica. (2008). Dom Ireneu Penna. Mosteiro de São Bento do Rio de Janeiro.

Fernandes, C. A. P. (Org.). (1968, abril/maio). Dom Irineu nos fala sobre a "Matemática Moderna”. O Leão (Jornal do Colégio de São Bento, Gente importante, p.3).

Gabinete do Prefeito do Distrito Federal-Br. Atos do Sr. Prefeito. (1938a, 31 de maio). Diário Oficial. 04 (jun). Seção II, 3713.

Gabinete do Prefeito do Distrito Federal-Br. Atos do Prefeito. (1938b, 14 de novembro). Comissionamento no estrangeiro. Portaria n. 15. Diário Oficial. 16 (nov.). Seção II, 7873.

Kilpatrick, J. (2012). The new math as an international phenomenon, ZDM, 44, 563-571.

Maria, L.V. (2007). D. Ireneu Penna: Apóstolo do Tomismo no Brasil. Aquinate, 5, 332-335. Retirado em 27 de janeiro de 2014, de http://www.aquinate.net/revista/caleidoscopio/ Entrevistas/05/02-d.\%20ireneu\%20penna.pdf

Miceli, S. (2001). Intelectuais à brasileira. São Paulo: Companhia das Letras.

Notícias da Prefeitura. (1938, 16 de junho). O Imparcial (p.2). 
Pedras Vivas. (2008). Revista dos Oblatos Seculares do Mosteiro de São Bento do Rio de Janeiro. (Mosteiro de São Bento). 9(47), 57-60.

Penna, I. (1967-1970). [Circular para] Pais ou responsáveis por alunos da $1^{\underline{a}}$ série ginasial do Colégio de São Bento (3 pp.). Tem por fim prestar contas e dar alguns esclarecimentos sobre a introdução do novo método de ensino de matemática no colégio.

Penna, I. (1968a, 3 de março). Entrevista. Boletim da Associação de Pais e Mestres do Colégio de Aplicação.

Penna, I. (1968b, 18 de agosto). Carta demissionária dirigida à diretora do I.F.C.S da UFRJ (1pp).

Penna, I. [197-] Apontamentos de Matemática. 4 v. Rio de Janeiro: Colégio de São Bento.

Penna, I. (1974, 10 de novembro) Com quantos métodos se faz uma didática à brasileira $O$ Globo (Caderno Educação, p. 26).

Prado, D. L. de A. (1991). Educação: ajudar a pensar, sim. Conscientizar, não. Rio de Janeiro: Agir.

Secretaria Geral de Educação e Cultura- Br. (1938, 16 de novembro). Boletim n. 432. Diário Oficial. 17 (nov.). Seção II, 7917.

Soares, F.S. (2001). O movimento da Matemática moderna no Brasil: avanço ou retrocesso. Dissertação de Mestrado em Matemática. Rio de Janeiro: Pontifícia Universidade Católica do Rio de Janeiro.

Universidade do Distrito Federal-Br. Faculdade de Educação (1938). Edital n. 3. Diário Oficial. 19 (jul). Seção II, 4817.

Universidade Federal do Rio de Janeiro-Br. (1969, 14 de outubro). Portarias (n. 760). Diário Oficial. 31 (out). Seção I - Parte II, 2875.

Recebido em: 30/11/2015

Aprovado em: 12/01/2016 